\title{
Naturally Crazy: Agency and Affect in One Flew Over The
}

\section{Cuckoo's Nest and Girl, Interrupted}

\author{
Kara Stone
}

\begin{abstract}
Girl, Interrupted is pop-culturally thought of as the poor-woman's One Flew Over The Cuckoo's Nest. The devaluation of female protagonists, women-centric media and bodily emotions form two similarly themed films into separate and distinct realm of artworks. Each film takes up specific gendered mental illnesses - Susanna is diagnosed with Borderline Personality Disorder, seven times more likely in women than men, and McMurphy with Anti-Social Personality Disorder, three times more likely in men than women. Both diagnoses use gendered rhetoric to categorize the individual's affects. The diagnoses are done through the DSM, the Diagnostic and Statistical Manual of Mental Disorders, a tool for categorization and pathologization of behaviours which dichotomizes "normal" and "healthy" to "crazy" and "ill". The films portray the naturalizing discourses used to create, diagnose and disseminate these illnesses. Avoiding Freudian psychoanalysis and opting for a feminist affect theory based approach, this paper will examine the construction and propagation of the normal/ill dichotomy, as well as how those narratives flow into other aspects of society such as the Men's Rights Movement and New Age women's body and health.
\end{abstract}

Keywords: Mental illness; mental health; affect, film; gender 
Toby: Let's not talk about this anymore

Susanna: Why?

Toby: Because it's stupid.

Girl, Interrupted (1999) is pop-culturally thought of as the poor-woman's One Flew Over The Cuckoo's Nest (1975). There are similarities between the narratives: set in mental institutions in which there are a variety of illnesses presented in the plentitude of B-characters, and purposefully ambiguous levels of "crazy" in the protagonists. Rebellion is a major theme within both. Ostensibly, the most significant difference is the gender and sex of the characters. Within mainstream cinema, there is a devaluation of female protagonists and women-centric media. This paper will argue that this stems from the devaluation of emotions themselves through their opposing medicalization and naturalization, and their genderization within filmic narratives. The methodological approach taken is that of feminist criticism and sexuality studies with a movement towards affect theory. Affect theory is a burgeoning academic lens exploring affect, first constructed by Deleuze (1966) as the somatic pre-cognitive recognizing of emotion as "a force, intensity, or the capacity to move and be moved." Queer and feminist scholars such as Ann Cvetkovich, Sara Ahmed, and Jasbir Puar have taken it up as a radical mode of analyzing both psychic and bodily feelings. Stemming from psychoanalysis but having moved well beyond, affect theory offers a new approach to studying mental health and wellness through non-dualism and breaking down binaries.

The categories of mental illness and the healthy/ill dichotomy are policed by social modes of control such as shame and fear. In One Flew Over The Cuckoo's Nest, 
Billy (Brad Dourif) stands up to Nurse Ratched (Louise Fletcher) after being found in bed with a woman:

Nurse Ratched: Aren't you ashamed?

Billy: No, I'm not.

[Applause from friends]

Nurse Ratched: You know Billy, what worries me is how your mother is going to take this.

Billy: Um, um, well, y-y-y-you d-d-d-don't have to t-t-t-tell her, Miss Ratched.

Agency and control, shame and acceptance intertwine differently in each of the films, yet they work to form neoliberalist structures of identity. These tools are used in medicalizing discourses to pathologize behaviours and affects, creating identity categories of ill and healthy.

Identification with diagnoses is a complex process. Individuals can fight, dismiss, excuse, instill, and interpolate their given/forces upon categorical label. Both disidentification (Muños, 1999) and identification (or the common negotiation between the two) effect the individual's sense of self, of their identity. Each film takes up specific gendered mental illnesses - Susanna, the protagonist of Girl, Interrupted, played by Winona Ryder, is diagnosed with Borderline Personality Disorder, seven times more likely in women than men. Jack Nicholson's R.P. "Mac” McMurphy, One Flew Over The Cuckoo's Nest's protagonist, has Anti-Social Personality Disorder, three times more likely in men than women. Borderline Personality Disorder is described as "a pattern of instability in interpersonal relationships, self-image, and affects, and marked impulsivity" and Anti-Social Personality Disorder is "a pattern of disregard for, and violation of, the rights of others" (DSM-IV, 1994). Lisa (Angelina Jolie), Susanna's friend and villain, 
like Mac, is a sociopath, which is another term for Anti-Social Personality Disorder. Lisa takes pride in her non-gender normative diagnosis, saying:

Lisa: We are very rare and we are mostly men.

Janet: Lisa thinks she's hot shit cause she's a sociopath.

Both Anti-Social Personality Disorder and Borderline Personality Disorders diagnoses use gendered rhetoric in their criteria to categorize the individual's affects. It is important to note the ways in which gender and non-heteronormative sexualities are pathologized within the Diagnostic and Statistical Manual of Mental Disorders (DSM), currently in its fifth edition. The DSM is a complete classification of mental disorders that are recognized by the American Psychiatric Association. The groups that determine the diagnostic categories consist of top researchers in their respective fields and all diagnostic categories that are included or revised are done so after a great deal of research. It is universally recognized though parts of Europe use a different system. The first DSM was published in 1952, the DSM-II in1968, DSM-III 1980, DSM-IV 1994, with the currently used DSM-IV-TR (text revision) published in 2000. To point out the dates and few and far-between editions is to show the slow-moving pace which may prevent it from staying up to date with new research, as well as progressive social movements and the rethinking of heteronormative values. Famously, homosexuality was removed as a mental disorder from the DSM in 1973. Subsequently, a new diagnosis Ego-Dystonic Homosexuality was created. Ego-Dystonic Homosexuality was indicated by "a persistent lack of heterosexual arousal, which the patient experienced as interfering with initiation or maintenance of wanted heterosexual relationships, and persistent distress from a sustained pattern of unwanted homosexual arousal" (UC Davis, Psychology). This was later removed entirely, 
yet its ghost remains under Sexual Disorders Not Otherwise Specified which include persistent and marked distress about one's sexual orientation. Other non-heteronormative behaviors were pathologized in the DSM-IV: Sexual Masochism, Sexual Sadism, Transvestic Fetishism and Gender Identity Disorder, to name a few extremely problematic ones. These categories work to pathologize, demonize, and 'other' nonnormative genders and sexualities while reinforcing the 'normal' and 'healthy' dominant way of being. Along with being a system of categorization, the DSM and American Psychiatrist Association's categorization is a tool to help psychologists and psychiatrists 'correct'. This paper is not a call to invalidate psychology and naturalize mental illness by stating it does not exist and neglect the colossal distress of the so-called mentally ill, but to examine how specific examples of categorization work to reinforce, strengthen, and collect members to the dominant norm.

Foucault's Madness and Civilization: A History of Insanity in the Age of Reason follows the differing constructions of mental illness in western civilization and the power structures that inform labeling and treatment. He states that before the eighteenth century the "therapeutics of madness did not function in the hospital, whose chief concern was to sever or to "correct"" and "it was no longer the presence of the truth that determined the cure, but a functional norm" (Foucualt, 1976). Foucault's work shows the importance of the non-permanent hegemonic societal influences of the constructions of mental illness. The DSM is portrayed as objective, simply describing what is already in society. In actuality, it helps construct, define, and change views and even experiences of mental illness. The rhetoric used to describe scientific studies has effects as well. Emily Martin (1991) in her paper The Egg and the Sperm: How Science has Constructed Romance 
Based on Stereotypical Male-Female Roles examines the ways in which scientific language can be used to reinforce stereotypical feminine and masculine cultural definitions. She works to "shine a bright light on the gender stereotypes hidden within the scientific language.” The field must recognize its own biases, cultural influences and epistemological position. Martin (1991) writes:

One clear feminist challenge is to wake up sleeping metaphors in science... Although the literary convention is to call such metaphors "dead," they are not so much dead as sleeping, hidden within the scientific content of texts - and all the more powerful for it. Waking up such metaphors, by becoming aware of when we are projecting cultural imagery onto what we study, will improve our ability to investigate and understand nature. Waking up such metaphors, by becoming aware of their implications, will rob them of their power to naturalize our social conventions about gender.Along with issuing a striking feminist call to action, Martin points out the naturalizing discourses used to normalize dominant gender conceptions. Mac and Susanna are diagnosed with personality disorders: Anti-Social Personality Disorder and Borderline Personality Disorder, respectively. The use of the word personality is problematic and troublesome for diagnoses; it pathologizes a whole person rather than their behaviours. It implies that there is something "wrong," in need of fixing with an individual's personality, their expression of identity. It lumps individuality into specific categories. This affects the patients' identification with the diagnosis and response to it. Changing a personality is a daunting task. In Girl, Interrupted, Susanna and other patients sneak into the psychologist's office to look at their files. For the first time, Susanna sees her diagnosis that was kept from her. 
Susanna: [reading from a book] "Borderline Personality Disorder. An instability of self-image, relationships and mood... uncertain about goals, impulsive in activities that are self-damaging, such as casual sex."

Lisa: I like that.

Susanna: "Social contrariness and a generally pessimistic attitude are often observed." Well that's me.

Lisa: That's everybody.

The rhetoric used has an effect on possible diagnoses. The DSM-IV recognizes this to an extent, stating "Antisocial Personality Disorder is much more common in males than in females. There has been some concern that Antisocial Personality Disorder may be under diagnosed in females, particularly because of the emphasis on aggressive items in the definition of Conduct Disorder"(DSM-IV, 1990). The DSM-IV pathologizes gendered personality traits, and bases its process of categorization on heteronormativity. What is "normal" and "healthy" are specific cultural norms - how men should act, how women should act. In fact, one of the criteria for Anti-Social Personality Disorder is a "failure to conform to social norms with respect to lawful behaviors"(DSM-IV, 1990). Anti-Social Personality Disorder and Borderline Personality Disorder, along with many mental illnesses, are defined by excess. Mac believes he is diagnosed because he is prone to “fight and fuck too much." It presents fighting and fucking as normative masculine behaviours, but taken too far and done too much. It is as though there is an acceptable and normal amount of "fighting" and "fucking" allowed for men by society and he has crossed that line. Borderline Personality Disorder lists excessive anger as a criterion: “inappropriate, intense anger or difficulty controlling anger”(DSM-IV,1990). The power structures within psychology and psychiatry (informed by social norms) are the controllers of what is considered "appropriate" emotional reactions. Impulsivity and 
instability are staples in both disorders as well. Those with Anti-Social Personality Disorder are stated that may have a history of many sexual partners and may never have sustained a monogamous relationship," and Borderline Personality Disorder patients have are believed to frequently participate in "impulsive," "reckless," and "potentially selfdamaging” sex (DSM-IV, 1990). There is a pathologization of non-normative sexual behaviours, hierarchizing monogamous and long-term relationships

Language is extremely important to definitions of mental illness. Jasbir Puar states, "the inability to 'communicate' functions as the single determinant of mental or cognitive impairment (thereby regulating the human/animal distinction), thus destabilizing the centrality of the human capacity for thought and cognition" (Puar, 2012). What is counted as communication is determined by the non-debilitated. There are many modes of communication yet only a few are recognized and desired by dominant powers. Foucault (1964) has a gloomy view:

...modern man no longer communicates with the madman ... There is no common language: or rather, it no longer exists; the constitution of madness as mental illness, at the end of the eighteenth century, bears witness to a rupture in a dialogue, gives the separation as already enacted, and expels from the memory all those imperfect words, of no fixed syntax, spoken falteringly, in which the exchange between madness and reason was carried out. The language of psychiatry, which is a monologue by reason about madness, could only have come into existence in such a silence.

The supposed lack of language and communication is part of the naturalization of the mentally ill. The character of Chief Bromden (Will Sampson) exemplifies the imposed 
disconnect of communication with the mentally ill; the Chief is considered mute, and no one questions it or tries to communicate with him in any way until Mac is institutionalized in his hospital. There are other means of communication and information transference, yet anything other than linear and logic based verbal communication is dismissed as lesser due to its operation in the bodily realm. Mentally ill individuals have been viewed in some historical periods as closer to animals than to humans, and currently there is a push towards describing the mentally ill as "natural," closer to nature, and closer to their animal selves (what Freud would call an "id"). This discourse works to naturalize the mentally ill as "less" than the "healthy" people. In Madness and Civilization (1964), Foucault states that in previous eras "madness in its ultimate form is man in immediate relation to his animality, without other reference, without any recourse." In the classical period, madness was not seen as an illness; in fact, the animality worked as a protection. Now, descriptions of the "rational animal" have changed meaning - "the unreason it suggested as the origin of all possible reason has entirely disappeared. Henceforth madness must obey the determinism of man perceived as a natural being in his very animality" (Foucault 1964). In opposition to animality, the ideal person is a "humanized human" (Mitchell, 2003) one who operates purely on reason and logic. They are seen as above any bodily functions and only communicate with verbal linear language. The mentally ill, however, are seen as "animalized humans," which is described as "the most troubling category of all, since all manner of brutalizations carries out by cultural prescription can serve to animalize humans, as can reminders of human beings' mammalian, or even merely bodily, organic existence" (Mitchell 2003). There is a devaluing of "naturalness" and a belief that men are creators 
upon nature and must disassociate aspects of human living. This disconnect between human and animal is wholly constructed through dominant social values. Judith Butler (2004) claims that any form of speaking is a bodily act, as it needs the body to perform. The depreciation of the animalesque can be seen within the structures of mental institutions themselves. They are seen as places outside of society, where young women like Susanna who have affairs with their parents' married friend can be sent to avoid scandal, yet also function in the public realm presenting madness as "a thing to look at" (Foucualt, 1964). There is an image of animality within the hospitals themselves, producing mentally ill patients as

beasts preyed upon by a natural frenzy: as if madness, at its extreme point, freed from that moral unreason in which its most attenuated forms are enclosed, managed to rejoin, by a paroxysm of strength, the immediate violence of animality. This model of animality prevailed in the asylums and gave them their cage-like aspect, their look of the menagerie (Foucault, 1964).

This treatment is seen as acceptable because it creates and continues the dividing distinction of human and animal based on the in/ability to linguistically communicate with society which stabilizes the importance of humans as defined by capacity of thought, cognition, and transference of information.

One Flew Over The Cuckoo's Nest employs a discourse of naturalization of mental illness so deeply that it seems to present that it does even exist, that the distress felt is purely from repression of their sexuality and to a lesser extent their emotions. Mac tells the other patients, “What do you think you are, for Chrissake, crazy or somethin'? Well you're not! You're not! You're no crazier than the average asshole out walkin' around on the streets and that's it." Furthermore, the tagline of the film is "If he's crazy, what does that make you?" To Mac and to the film itself, everyone is "crazy," and 
therefore no one is "actually crazy" and in need of treatment. This sort of discourse dismisses the very real and harmful states of distress felt by those with mental illness. The film also naturalizes problematic gendered behaviours. Mac is arrested for having sex with an underage girl, explaining it by saying,

She was fifteen years old, going on thirty-five, Doc, and she told me she was eighteen, she was very willing, I practically had to take to sewing my pants shut. Between you and me, uh, she might have been fifteen, but when you get that little red beaver right up there in front of you, I don't think it's crazy at all and I don't think you do either. No man alive could resist that, and that's why I got into jail to begin with. And now they're telling me I'm crazy over here because I don't sit there like a goddamn vegetable. Don't make a bit of sense to me. If that's what being crazy is, then I'm senseless, out of it, gone-down-the-road, wacko. But no more, no less, that's it.

The audience is supposed to relate and to accept Mac as normal and mentally healthy, yet he excuses statutory rape as a natural male desire. Evidently, Mac is "crazy" because he is sexually repressed. He encourages change within the hospital and patients by creating stereotypically masculine hobbies. He tries to restore the men's supposed masculinity through gambling, drinking, sex, and fishing, all the while villianizing Nurse Ratched as the oppressor of masculinity. Girl, Interrupted naturalizes aspects of mental illness as well, but with a more subtle hand. At the end of the film, Susanna is discharged and she says in her voice over, "Declared healthy and sent back into the world. My final diagnosis: a recovered borderline. What that means, I still don't know. Was I ever crazy? Maybe. Or maybe life is." This dismisses individual experiences and affects by propagating the notions that everything and everyone is "crazy." The dismissal of the category of "mentally ill" may seem politically progressive, but it assimilates and invalidates personal experiences. The extremely distressing emotions felt are real and influential to the outer world. Emotions $d o$ things. Rather than seeing them as 
“psychological dispositions, we need to consider how they work, in concrete and particular ways, to mediate the relationship between the psychic and the social, and between the individual and the collective" (Ahmed 2004). Affect stimulates reason and logic and motivates affective change. "Humanized humans" may be perceived as having thoughts and actions distinct from bodily emotions, but they cannot be untied. Behind all communication, there is an affect.

In linearly constructed television and film, cause and effect are necessary for intelligibility, and emotions that are not "purposeful" or part of the greater narrative are seen as "excessive." The causes and effects must be understandable in a logic and reasonbased system of action and communication, yet in actuality emotions themselves help create and produce all causes and effects. Sara Ahmad challenges the assumption that "emotions are a private matter, that they simply belong to individuals, or even that they come from within and then move outward toward others. It suggests that emotions are not simply 'within' or 'without' but that they create the very effect of the surfaces or boundaries of bodies and worlds" (Ahmed, 2004). Within standard mechanisms of film structure, the 'cause' is an outside force that changes something for the protagonist. Every action must have a cause and effect lest it be labeled as excess, pointless, useless, and unnecessary. A piece is considered to be successful, in terms of formal structure, if every detail is part of the overarching narrative. Every action of every character must make 'logical sense' to the viewer; every emotional state the protagonist is in must be accounted for. In this system, emotions are only triggered from the outside and then consequently felt within. Characters do not simply wake up in a poor mood without it meaning something greater or beyond itself. 
Emotions and affect are essential to identity formation. Ahmad (2004) writes “emotions play a crucial role in the 'surfacing' of individual and collective bodies through the way in which emotions circulate between bodies and signs." Puar (2012) theorizes that there are "diverse switch-points of the activation in the body" that move emotions between the self and outside forces in a more back and forth manner. Bodily and emotional communication can happen through a sort of osmosis, refuting the causeand-effect mode of understanding emotion and action. This means that a feeling is not triggered within an individual solely by an outside force; emotions can "start" inside and move outwards, and then back in again infinitely. This does not mean that the emotion resides exclusively in the individual; it is the "circulation of signs" (Ahmed, 2004) that produces affective economies. Behind every cause there is an affect.

Collectively, affect can be used to stimulate political change. Ann Cvetkovich $(2007,2012)$ theorizes that there can be a "political depression" which is "the sense that customary forms of political response, including direct action and critical analysis, are no longer working either to change the world or to make us feel better." The concept of political depression is not meant to be altogether depressing. The aspiration is to "depathologize negative affects so that they can be seen as a possible resource for political action rather than as its antithesis. This is not, however, to suggest that depression is thereby converted into a positive experience; it retains its associations with inertia and despair, if not apathy and indifference, but these affects become sites of publicity and community formation" (Cvetkovich, 2007). In Girl, Interrupted and One Flew Over The Cuckoo's Nest, emotions are felt collectively. The patients utilize their feelings of repression and frustration and direct them towards mini rebellions. From Mac 
and his fellow patients taking over the floor for a party to Susanna, Lisa, and friends barking at the wife of Susanna's lover when she publicly lectures her, breaking hospital or social rules perform as collective politics acts produced through affect. The goal is not to transform, release or "get rid of" their "excessive" emotions but to funnel them into political change.

Though there are emphases on the power of the collective for feeling and transferring emotions and motivating social change, this progressive discourse interacts with a neoliberalist approach to mental illness residing solely in individuals. Because of the ways in which language is constructed, emotions are seen as individual property. They play a role in the "surfacing" of individual and collective bodies through "the way in which emotions circulate between bodies and signs. Such an argument clearly challenges any assumption that emotions are a private matter, that they simply belong to individuals, or even that they come from within and then move outward toward others. It suggests that emotions are not simply "within" or "without" but that they create the very effect of the surfaces or boundaries of bodies and worlds" (Ahmed, 2004). Although this is the case, neoliberalist notions of agency are dominant and overshadow other modes of understanding. In discourses surrounding mental illness, there are damaging concepts put forth that construct the distressing feelings as solely residing in the individual, pushing self-responsibility. At present, it is seen that individuals must be constantly working on themselves and practicing self-surveillance in order to monitor their in/sanity. Terms like "it gets better," "progress," and "work at it" perpetuate this myth that mental illness is yet another obstacle to overcome in becoming the perfect neoliberal citizen. It proposes that 
there is a choice between "healthy" and ill. Valerie (Whoopi Goldberg), the head nurse in Girl, Interrupted tells Susanna:

Valerie: You know, I can take a lot of crazy shit from a lot of crazy people. But you - you're not crazy.

Susanna: Oh yeah? Then what's wrong with me? What the fuck is going on inside my head? Tell me, Dr. Val, what's your diag-nonsense?

Valerie: You are a lazy, self-indulgent, little girl, who is making herself crazy!

Here is Susanna talking to her psychologist, Doctor Wick:

Susanna: I'm ambivalent. In fact that's my new favorite word.

Dr. Wick: Do you know what that means, ambivalence?

Susanna: I don't care.

Dr. Wick: If it's your favorite word, I would've thought you would...

Susanna: It means I don't care. That's what it means.

Dr. Wick: On the contrary, Susanna. Ambivalence suggests strong feelings... in opposition. The prefix, as in "ambidextrous," means "both." The rest of it, in Latin, means "vigor." The word suggests that you are torn... between two opposing courses of action.

Susanna: Will I stay or will I go?

Dr. Wick: Am I sane... or, am I crazy?

Susanna: Those aren't courses of action.

Dr. Wick: They can be, dear - for some.

"Craziness" and even emotions themselves are presented as a choice to be made by the individual - a choice with one right answer and one wrong answer. The dichotomy of "healthy" and mentally ill leaves no middle or in-between space. Susanna cannot be "a little crazy" - she either is or she is not, and it is her responsibility to make sure she chooses the "right" answer, which is to be "healthy" and "sane." In One Flew Over The 
Cuckoo's Nest, Mac chooses to be labeled as "crazy" in order to avoid going to prison, yet is shocked and looks down upon the patients who voluntarily commit themselves and take on the negative descriptor. In his naturalizing eyes, "craziness" does not exist and is something one chooses for themselves.

The strict polarization of "healthy" and "ill" helps to regulate social behavioural norms in order to profit capitalism. Jasbir Puar (2012) explains that in the United States, the number one reason for filing for bankruptcy is due to the cost of medical expenses. Mental illness is profitable, but only in the demand to "get better," "recover," or "overcome". Lisa addresses this by saying,

Lisa: That's what ther-raping is all about. That's why Freud's picture is on every shrink's wall. You create a fucking industry. You lie down, you confess your secrets and you're saved. Ca-ching. The more you confess the more they think about setting you free."

Susanna: What if you don't have a secret

Lisa: Then you're a lifer like me

This again plays into the ill/healthy dichotomy; if one does not have an illness that can be "overcome" by standard health industries and the individual's affects cannot be assimilated into public society, then one is lost. The plentitude of categories in the DSMIV do not cover every affective experience and emotional state but if one does not fit into the set types, help is hard to find. Citizens are forced to negotiate the capitalist, neoliberalist mental health system. Susanna meets a man at a party and tries to convince him to stop hitting on her by telling him she is "crazy." In response, he says:

Tony: Do you see purple people? My friend, he saw purple people. And so the state came and took him away. He didn't like that. Some time went by and, and he told 'em he didn't see purple people no more.

Susanna: He got better. 
Tony: Nah, he still sees 'em.

The prevalence and intensity of the systematic control of public emotion work to standardize social norms through the impossible categorization of affect. Naturalizing and medicalizing discourses work in different way to pathologize gender and nonheteronormative sexualities, yet both utilize neoliberalist notions of agency and individual responsibility to restrict "excessive" behaviours. The affective force is instrumental in the process of action and doing. We must push the notion selfresponsibility for mental health far away from us and look to a more affective and effective approach of a collectivity and connectivity - with both other people and the duality of body and mind. 


\section{References}

Ahmed, Sara. (2004) Affective Economies. Social Text, vol. 22, 117-139.

Berlant Lauren. (2007) Slow Death. Critical Inquiry, Vol. 33. 754-80.

Bishop, R. Scott. (2004) Mindfulness: A Proposed Operation Definition. Clinical Psychology: Science and Practice. Vol. 11, No.3 pp 230-24.

Butler, Judith. (2004) Undoing Gender. Psychology Press. United States .

Cvetkvich, Ann (2012) Depression: A Public Feeling. Duke University Press, Durham \& London

Cvetkovish, Ann. (2007) Public Feelings, South Atlantic Quarterly, Vol. 106.3. 459-68.

Finkler, Kaja (2001) The Kin in the Gene: Medicalization of Family and Kinship in American Society, Current Anthropology, Vol. 42, No. 2.

Foucault, Michel. (1990) The History of Sexuality, Vol 1: An Introduction. Pantheon Books.

Hepburn, Sharon J. (1988) Western Minds, Foreign Bodies, Medical Anthropology Quarterly. Vol. 2, Iss. 1. March.

Hodmann, Stefan G. (2010) The Effect of Mindfulness-Based Therapy on Anxiety and Depression: A Meta-Analytic Review. Journal of Consulting and Clinical Psychology. Vol. 78(2): 169-183.

Kimmel, Michael and Michael Kaufman, (1995) Weekend Warriors: The New Men's Movement, The Politics of Manhood: Profeminist Men Respond to the Mythopoetic Men's Movement (And the Mythopoetic Leaders Answer). Temple University Press.

de Lauretis, Teresa. (1985) "Rethinking Women's Cinema: Aesthetics and Feminist Theory", New German Critique, No. 34, Winter.

Martin, Emily (1991_ The Egg and The Sperm" How Science has Constructed Romance Based on Stereotypical Male-Female Roles, Signs. Vol. 16 No. 3. the University of Chicago Press.

Mitchell, Cary (2003) Subject To Sacrifice Psychoanalysis, and the Discourse of Species in Jonathan Demme's The Silence of the Lambs, Animal Rites: American Culture, the Discourse of Species and Posthumanist Theory. University of Chicago Press. USA. 
Mulvey, Laura. (1975) Visual Pleasure and Narrative Cinema, Screen. Vol. 16. No.3 Autumn.

Puar, Jasbir K. (2012) Coda: The Cost of Getting Better: Suicide, Sensation, Switchpoints GLQ: A Journal of Lesbian and Gay Studies, Vol. 18.1, 149-158.

Puar, Jasbir K. (2005) Queer Times, Queer Assemblages. Social Text, Vol 23, No. 3-4, 121 140.

UC Davis, University of California Pyshcology. Facts About Homosexuality and Mental Health.<http://psychology.ucdavis.edu/rainbow/html/facts_mental_health.html $>$

Williams, Linda. (1991) Film Bodies: Gender Genre and Excess, Film Quarterly. Vol. 44, No. 4. Summer. 